\title{
Prevalance of Gastrointestinal Protozoa of Cats in Animal Hospital and Animal Clinic in Surabaya
}

\section{Prevalensi Protozoa Saluran Pencernaan Kucing Pasien Rumah Sakit dan Klinik Hewan di Surabaya}

\author{
${ }^{1)}$ Amara Lintang Pagati, 2) Lucia Tri Suwanti, 3) Chairul Anwar, ${ }^{4)}$ Wiwik Misaco Yuniarti, 3)Sarmanu, \\ ${ }^{2}$ Endang Suprihati \\ ${ }^{1)}$ Student, ${ }^{2)}$ Department of Veterinary Parasitology, ${ }^{3}$ Department of Veterinary Anatomy, ${ }^{4}$ Department \\ of Veterinary Clinic. Faculty of Veterinary Medicine, Airlangga University.
}

\begin{abstract}
Research of gastrointestinal protozoan in cats at Surabaya are still limited. Protozoa infection of the gastrointestinal tract can cause diarrhea and even zoonosis. This research aimed to identify and determine the prevalence of protozoan in cats in animal hostptal and animal clinic in Surabaya. Ninety fecal samples were collected from 2 animal clinic and one animal hospital. Samples were examined e wet mount (native, sedimentation, and floatation) and (Ziehl Nellsen) stain. Protozoa was identified by using a light microscope with 40ox and 10oox magnification. The result showed $68,89 \%$ of samples were positively infected by gastrointestinal protozoa. The protozoa were Blastocystis sp, Cryptosporidium sp, Giardia sp, and Eimeria sp. By chi square test, there was not significant differences the prevalence of gastrointestinal protozoan in cat between sex, age, breed, and diarrhea status.
\end{abstract}

Key words : prevalence, gastrointestinal protozoa, cat

\section{Pendahuluan}

Laporan penelitian di Indonesia mengenai infeksi protozoa saluran pencernaan yang menyerang hewan kecil terutama pada kucing masih sedikit (Pabundu, 2007). Di Indonesia laporan mengenai infeksi protozoa saluran pencernaan yang menyerang kucing khususnya di daerah Surabaya sebagian besar hanya terdapat pada kucing-kucing liar dan kucing yang dijual di pasar maupun pet shop, sedangkan penelitian pada kucing di Rumah Sakit Hewan dan Klinik Hewan masih sedikit.

Infeksi protozoa pada saluran pencernaan tidak selalu menampakkan gejala klinis, hanya pada infestasi yang berat dapat menyebabkan diare, nafsu makan dan daya tahan tubuh menurun, serta gangguan pertumbuhan pada hewan muda (Lukiswanto dan Yuniarti, 2013). Kejadian penyakit yang disebabkan protozoa saluran pencernaan sangat perlu diperhatikan mengingat penyebaran penyakit yang luas dan penularan yang begitu cepat dan beberapa penyakit bersifat zoonosis. Kedekatan antara kucing dan manusia mempermudah penularan penyakit yang menyerang kucing yang dapat menular ke manusia bersifat zoonosis. Protozoa saluran pencernaan yang bersifat zoonosis pada kucing antara lain Giardia, Cryptosporidium dan Toxoplasma gondii (Subekti, 200o).

Beberapa jenis protozoa saluran pencernaan yang menyerang kucing adalah genus Entamoeba, Balantidium, Toxoplasma, Isospora, Eimeria, Giardia, Trichomonas dan Cryptosporidium (Levine, 1995). Penelitian yang dilakukan Sucitrayani dkk. (2014) menemukan infeksi protozoa saluran pencernaan kucing sebanyak 31,3\% dari 8o ekor kucing liar dan peliharaan dan protozoa yang ditemukan adalah Giardia felis, Cryptosporidium felis, Sarcocystis spp, Hammondia hamondi, Toxoplasma gondii dan Isospora spp. Menurut penelitian Bendryman (2000) dan Pabundu (2007) melaporkan angka prevalensi infeksi protozoa pada kucing liar di beberapa wilayah di Surabaya sebesar 2,5\% dari 40 ekor kucing dan protozoa yang ditemukan Isospora felis, Isospora rivolta dan Toxoplasma gondii. 
Sucitrayani dkk (2014) melaporkan bahwa perbandingan prevalensi infeksi protozoa saluran pencernaan pada kucing berdasarkan jenis kelamin menunjukkan angka prevalensi infeksi protozoa pada kucing betina dan kucing jantan tidak berbeda nyata. Menurut Yudhie (2010) umur kucing berpengaruh terhadap prevalensi infeksi protozoa saluran pencernaan pada kucing, kucing muda prevalensi infeksi tinggi dibandingkan kucing tua. Susanty (2005) melaporkan kucing kampung sebagai hewan peliharaan memiliki pemeliharaan yang cukup mudah, lebih tahan dengan berbagai macam penyakit dan memiliki daya adaptasi yang cukup tinggi terhadap infeksi parasit bila dibandingkan dengan kucing ras.

penelitian ini bertujuan untuk mengetahui prevalensi protozoa saluran pencernaan pada kucing pasien Rumah Sakit dan Klinik Hewan di Surabaya.

\section{Metode Penelitian}

\section{Tempat dan Waktu Penelitian}

Pengambilan sampel feses dilaksanakan di dua Klinik Hewan yaitu Fauna Medika dan Puppy, dan satu Rumah Sakit Hewan Pendidikan Universitas Airlangga di Surabaya. Pemeriksaan sampel feses dilaksanakan di Laboratorium Parasitologi Veteriner Fakultas Kedokteran Hewan, Universitas Airlangga. Penelitian dilaksanakan pada bulan Agustus sampai November 2017.

\section{Prosedur Penelitian}

Sembilan puluh feses sampel, dikoleksi dari masing-masing tempat, tiap tempat 30 sampel. Sampel diperoleh dengan mengambil langsung feses segar dari tempat hewan defekasi. kira-kira 5-10 gram dengan penambahan kalium bikarbonat $3 \%$ sebagai bahan pengawet kemudian dimasukkan dalam pot plastik. Tiap pot diberi label yang mencantumkan identitas tiap kucing yang terdiri dari nama hewan, umur hewan, jenis kelamin hewan, jenis ras, kondisi feses kucing diare dan tidak diare, serta tempat dan tanggal pengambilan sampel.

Sampel diperiksa di Departemen Parasitologi Veteriner Fakultas Kedokteran Hewan, Universitas Airlangga. Pemeriksaan sampel dilakukan dengan metode natif, sedimentasi, apung dan pewarnaan tahan asam (Ziehl Neelsen). Jika menemukan ookista yang belum bersporulasi dilakukan sporulasi. Penentuan jenis protozoa dengan mengamati morfologi bentuk dan ukuran protozoa. Protozoa diukur dan diamati dengan mikroskop yang tersambung dengan optilab image. Data dinyatakan positif apabila pada salah satu pemeriksaan menemukan protozoa.

prevalesi dianalisis menggunakan chi-square dengan program SPSS untuk membedakan berdasarkan jenis kelamin, umur, ras, dan kondisi feses dan diuji menggunakan chi-square dengan program SPSS.

\section{Hasil dan Pembahasan}

Dari 90 sampel feses kucing 62 sampel feses dinyatakan positif, atau angka prevalensi infeksi protozoa pada kucing sebesar 68,89\% (Tabel 1). Angka prevalensi pada penelitian lebih tinggi dibandingkan dengan penelitian yang dilakukan Sucitrayani dkk (2014) di Denpasar yang melaporkan prevalensi protozoa saluran pencernaan pada kucing lokal sebesar 31,3\% dari 8o sampel yang diperiksa. Perbedaan tersebut kemungkinan disebabkan karena perbedaan jenis kucing yang diteliti. Penelitian yang dilakukan di Surabaya menggunakan kucing yang telah terindikasi sakit berdasarkan anamnesa dari data pasien Rumah Sakit Hewan dan Klinik Hewan di Surabaya. Penelitian Sucitrayani dkk (2014) menggunakan kucing liar dan kucing peliharaan yang mengabaikan status kesehatannya.

Tabel 1. Prevalensi Protozoa Saluran Pencernaan pada Kucing Pasien Rumah Sakit dan Klinik Hewan Puppy di Surabaya.

\begin{tabular}{ccc}
\hline Hasil & Jumlah Sampel & Presentase (\%) \\
\hline Positif & 62 & $68,89 \%$ \\
Negatif & 28 & $31,11 \%$ \\
\hline Total & 90 & $100 \%$
\end{tabular}

Protozoa yang ditemukan pada penelitian ini adalah Eimeria sp, Cryptosporidium sp, Giardia sp dan Blastocystis sp. Identifikasi protozoa dilakukan dengan melihat morfologi, bentuk dan ukuran protozoa dengan mengamati morfologi bentuk dan ukuran protozoa. Protozoa diukur dan diamati dengan mikroskop yang tersambung dengan optilab image.

Stadium ookista Eimeria yang ditemukan pada penelitian ini berukuran 23,13 $\mu \mathrm{m}-25,6 \mu \mathrm{m}$, berbentuk oval, memiliki dinding tipis dan halus, memiliki mikropil dan mengandung empat sporo 
kista. Hal tersebut sesuai dengan yang diungkapkan Suwanti dkk (2012) yang menyatakan bahwa ookista Eimeria sp berbentuk bulat, subperikal, ovoid atau ellipsoid dengan ukuran yang beragam sesuai dengan spesiesnya, dimana pada Eimeria $s p$ pada kucing mempunyai mikrofil dan 4 sporokista dan tiap-tiap sporokista mengandung 2 sporozoit. Menurut Levine (1995) yang menginfeksi kucing adalah spesies Eimeria feline dan Eimeria cati. Eimeria feline stadium ookista berukuran antara 26-43 dan Eimeria cati berukuran antara 23-29 $\mu \mathrm{m}$. Berdasarkan ciri-ciri tersebut Eimeria yang ditemukan pada penelitian ini kemungkinan adalah Eimeria cati. Untuk mengetahui spesies secara jelas perlu penelitian lebih lanjut dengan metode yang lebih akurat.

Ookista Cryptosporidium sp yang ditemukan pada penelitian ini berukuran 7,32 $\mu \mathrm{m}-7,93 \mu \mathrm{m}$ dan terlihat jelas empat sporozoit yang tidak mempunyai sporokista. Cryptosporidium yang menginfeksi kucing merupakan golongan spesies Cryptosporidium felis memiliki ukuran antara 7-9 $\mu \mathrm{m}$, mengandung empat sporozoit telanjang dan tidak mempunyai sporokista (Levine, 1995). Berdasarkan ciri-ciri tersebut Cryptosporidium yang ditemukan pada penelitian ini kemungkinan adalah Cryptosporidium felis. Untuk mengetahui spesies secara jelas perlu penelitian lebih lanjut dengan metode yang lebih akurat.

Giardia yang ditemukan adalah stadium kista berukuran 45,76 - 47,70 $\mu \mathrm{m}$ memiliki inti dan serabut. Hal tersebut sesuai dengan yang diungkapkan Levine (1995) bahwa Giardia pada stadium kista mempunyai dua sampai empat inti dan sejumlah sisa serabut dari organel tropozoit dan Giardia yang menginfeksi kucing adalah Giardia cati. Giardia bersifat zoonosis, artinya jika kucing peliharaan terinfeksi Giardia bisa menular ke manusia maupun hewan peliharaan lain (Barr sc et al, 1994).

Genus Blastocystis pada penelitian ini ditemukan dua stadium yakni stadium vakuolar dan stadium granular. Blastocystis yang ditemukan memiliki ukuran antara 7,9 - 36,54 $\mu \mathrm{m}$. Hal tersebut sesuai dengan hasil penelitian dari Duda et al (1998) yang menyatakan bahwa Blastocystis $s p$ pada kucing stadium vakuolar memiliki ukuran 2-10 $\mu \mathrm{m}$ dan stadium granular memiliki ukuran 3,5-30 $\mu \mathrm{m}$.

Prevalensi setiap spesies di Rumah Sakit Hewan Universitas Airlangga, Klinik Hewan Fauna Medika dan Klinik Hewan Puppy di Surabaya tertera pada Tabel 2. Sedangkan Prevalensi setiap spesies pada masing-masing prevalensi setiap spesies di Rumah Sakit Hewan Universitas Airlangga, Klinik Hewan Fauna Medika dan Klinik Hewan Puppy di Surabaya tertera pada Tabel 3 .

Tabel 2. Prevalensi Setiap Spesies Protozoa Saluran Pencernaan Kucing Pasien Rumah Sakit Hewan dan Klinik Hewan di Surabaya

\begin{tabular}{lccc}
\hline Spesies & $\begin{array}{c}\text { Sampel } \\
\text { Positif }\end{array}$ & $\begin{array}{c}\text { Jumlah } \\
\text { Sampel }\end{array}$ & $\begin{array}{c}\text { Prevale } \\
\text { nsi (\%) }\end{array}$ \\
\hline Eimeria sp. & 4 & 90 & $4,44 \%$ \\
Giardia sp. & 4 & 90 & $4,44 \%$ \\
Blastocystis sp. & 54 & 90 & $53,33 \%$ \\
Cryptosporidium & 13 & 90 & $14,4 \%$ \\
sp. & & & \\
\hline
\end{tabular}

Tabel 3. Prevalensi Setiap Spesies Protozoa Saluran Pencernaan Kucing Pasien di Masing-Masing Tempat Pengambilan Sampel

\begin{tabular}{lccc}
\hline \multicolumn{1}{c}{ Spesies } & \multicolumn{3}{c}{ Jumlah positif dan presentase } \\
\hline & $\begin{array}{c}\text { Rumah Sakit Hewan } \\
\text { Universitas Airlangga }\end{array}$ & $\begin{array}{c}\text { Klinik Hewan } \\
\text { Fauna Medika }\end{array}$ & $\begin{array}{c}\text { Klinik Hewan } \\
\text { puppy }\end{array}$ \\
\hline Infeksi Tunggal & & & \\
Eimeria sp. & $\mathrm{o} / 30(\mathrm{o} \%)$ & $3 / 30(10 \%)$ & $\mathrm{o} / 30(\mathrm{o} \%)$ \\
Giardia sp. & $\mathrm{o} / 30(\mathrm{o} \%)$ & $\mathrm{o} / 30(\mathrm{o} \%)$ & $\mathrm{o} / 30(\mathrm{o} \%)$ \\
Blastocystis sp. & $14 / 30(46,6 \%)$ & $13 / 30(43,3 \%)$ & $15 / 30(50 \%)$ \\
Cryptosporidium sp. & $3 / 30(10 \%)$ & $4 / 30(13,3 \%)$ & $2 / 30(6,67 \%)$ \\
Infeksi Campuran & $1 / 30(3,33 \%)$ & & \\
Giardia sp. + Eimeria sp. & $2 / 30,(6,67 \%)$ & $\mathrm{o} / 30(\mathrm{o} \%)$ & $\mathrm{o} / 30(\mathrm{o} \%)$ \\
Blastocystis sp. + Giardia sp. & $3 / 30(10 \%)$ & $\mathrm{o} / 30(\mathrm{o} \%)$ & $\mathrm{o} / 30(\mathrm{o} \%)$ \\
Blastocystis sp. + Cryptosporidium sp. & $76,6 \%$ & $66,6 \%)$ & $1 / 30(3,33 \%)$ \\
\hline Total & & & $60 \%$
\end{tabular}

Prevalance of Gastrointestinal Protozoa of Cats in Animal Hospital,, 
Berdasarkan hasil analisis chi square prevalensi infeksi protozoa kucing jenis kelamin menunjukkan tidak adanya perbedaan nyata ( $>>0,05)$. Hal tersebut menunjukkan bahwa prevalensi kucing jantan dan kucing betina sama atau jenis kelamin berpengaruh terhadap infeksi protozoa saluran pencernaan. Dalam penelitian ini hanya membandingkan tingkat kejadian positif sampel terhadap perbedaan jenis kelamin sehingga perlu penelitian lebih lanjut untuk memastikan penyebab hal tersebut dapat terjadi. Hasil penelitian ini serupa dengan penelitian yang dilakukan Sucitrayani dkk (2014) melaporkan bahwa infeksi protozoa saluran pencernaan pada kucing jantan tidak berbeda nyata pada kucing betina. Prevalensi Infeksi Protozoa Saluran Pencrnaan Kucing Berdasarkan Jenis Kelamin dapat dilihat pada Tabel 4 .
Berdasarkan hasil analisis chi square prevalensi infeksi protozoa saluran pencernaan berdasarkan umur kucing tidak berpengaruh terhadap prevalensi (p>0,05). Hal tersebut menunjukkan bahwa perbedaan umur tidak berpengaruh terhadap prevalensi infeksi protozoa saluran pencernaan. Pada genus Eimeria tidak terdapat sampel positif. Hal ini disebabkan genus Eimeria merupakan salah satu masalah utama hewan muda karena pada hewan yang berumur tua kekebalan tubuhnya lebih baik dalam proteksi agen infeksi (Susilo dkk, 2014). Hasil penelitian ini serupa dengan penelitian (Yudhie, 2010) yang juga membagi umur kucing di bawah 1 tahun dan di atas 1 tahun dan hasilnya bahwa umur tidak berpengaruh pada prevalensi infeksi protozoa saluran pencernaan. Prevalensi infeksi protozoa saluran pencernaan berdasarkan umur kucing dapat dilihat pada Tabel 5 .

Tabel 4. Prevalensi Infeksi Protozoa Saluran Pencernaan Kucing Berdasarkan Jenis Kelamin

\begin{tabular}{clcc}
\hline Jenis Kelamin & \multicolumn{1}{c}{ Spesies } & Jumlah Positif & Prevalensi (\%) \\
\hline \multirow{3}{*}{ Betina } & Blastocystis sp. & $23 / 42$ & $54,76 \%$ \\
& Cryptosporidium sp. & $8 / 42$ & $19,04 \%$ \\
& Eimeria sp. & $2 / 42$ & $4,76 \%$ \\
& Giardia sp. & $1 / 42$ & $2,38 \%$ \\
& Blastocystis sp. & $25 / 48$ & $52,08 \%$ \\
& Cryptosporidium sp. & $5 / 48$ & $10,41 \%$ \\
& Giardia sp. & $3 / 48$ & $6,25 \%$ \\
& Eimeria sp. & $2 / 48$ & $4,167 \%$ \\
\hline
\end{tabular}

Total 69/9o $(76,67 \%)$

Tabel 5. Prevalensi Infeksi Protozoa Saluran Pencernaan Berdasarkan Umur Kucing

\begin{tabular}{clcc}
\hline \multicolumn{1}{c}{ Umur } & \multicolumn{1}{c}{ Spesies } & Jumlah Positif & Prevalensi (\%) \\
\hline \multirow{5}{*}{ Di bawah 1 Tahun } & Blastocystis sp. & $30 / 54$ & $55,56 \%$ \\
& Cryptosporidium sp. & $8 / 54$ & $14,81 \%$ \\
\cline { 2 - 3 } & Eimeria sp. & $4 / 54$ & $7,407 \%$ \\
& Giardia sp. & $3 / 54$ & $5,55 \%$ \\
\cline { 2 - 2 } Di atas 1 Tahun & Blastocystis sp. & $18 / 36$ & $50 \%$ \\
& Cryptosporidium sp. & $5 / 36$ & $13,89 \%$ \\
& Giardia sp. & $1 / 36$ & $2,78 \%$ \\
\hline
\end{tabular}

Total $\quad 69 / 90(76,67 \%)$


Berdasarkan hasil analisis chi square prevalensi infeksi protozoa berdasarkan ras kucing pasien Rumah Sakit Hewan Universitas Airlangga, Klinik Hewan Fauna Medika dan Klinik Hewan Puppy di Surabaya pada perbandingan ras terhadap infeksi protozoa saluran pencernaan menunjukkan tidak adanya perbedaan nyata di (Tabel 6) antara kucing domestik, ras persia dan campuran $(\mathrm{p}>0,05)$. Hal tersebut menunjukkan bahwa perbedaan ras kucing tidak berpengaruh terhadap prevalensi infeksi protozoa saluran pencernaan. Kemungkinan hal ini dapat terjadi karena pola pemeliharaan, dan pemberian pakan yang sama. Hasil penelitian ini serupa dengan penelitian yang dilakukan Mirzae (2010) pada sampel feses domestik dari 20 sampel, 5 sampel positif terinfeksi protozoa saluran pencernaan (25\%) dan ras persia dari 8o sampel, 21 sampel positif terinfeksi protozoa saluran pencernaan $(26,2 \%)$ yang juga membagi ras kucing domestic dan persia dan hasilnya bahwa jenis ras tidak berpengaruh pada prevalensi infeksi protozoa saluran pencernaan. Prevalensi infeksi protozoa saluran pencernaan berdasarkan ras kucing tertera pada Tabel 6 .

Tabel 6. Prevalensi Infeksi Protozoa Saluran Pencernaan Berdasarkan Ras Kucing

\begin{tabular}{llcc}
\hline Jenis Ras & \multicolumn{1}{c}{ Spesies } & $\begin{array}{c}\text { Jumlah } \\
\text { Positif }\end{array}$ & $\begin{array}{c}\text { Preval } \\
\text { ensi } \\
(\%)\end{array}$ \\
\hline & $\begin{array}{l}\text { Blastocystis sp. } \\
\text { Cryptosporidium }\end{array}$ & $13 / 23$ & $56,52 \%$ \\
$\begin{array}{l}\text { Domestik } \\
\text { (Kucing }\end{array}$ & sp. & $6 / 23$ & $26,08 \%$ \\
kampung) & Eimeria sp. & $2 / 23$ & $8,69 \%$ \\
& Giardia sp. & $2 / 23$ & $8,69 \%$ \\
& Blastocystis sp. & $31 / 58$ & $53,44 \%$ \\
& Cryptosporidium & & \\
& sp. & $7 / 58$ & $12,06 \%$ \\
& Eimeria sp. & $2 / 58$ & $3,44 \%$ \\
Campuran & Giardia sp. & $2 / 58$ & $3,44 \%$ \\
Blastocystis sp. & $4 / 9$ & $44,4 \%$ \\
\hline \multicolumn{2}{c}{$69 / 90(76,67 \%)$} \\
\end{tabular}

Berdasarkan hasil analisis chi square prevalensi infeksi protozoa berdasarkan kondisi feses kucing pasien Rumah Sakit Hewan Universitas Airlangga, Klinik Hewan Fauna Medika dan Klinik Hewan Puppy di Surabaya pada perbandingan kondisi feses terhadap infeksi protozoa saluran pencernaan menunjukkan tidak adanya perbedaan nyata Hal tersebut menunjukkan bahwa perbedaan kondisi feses tidak berpengaruh terhadap infeksi protozoa saluran pencernaan. Hal ini disebabkan karena protozoa saluran tidak selalu menampakkan gejala klinis atau bersifat asimtomatis, hanya pada infestasi yang berat dapat menyebabkan diare, nafsu makan dan daya tahan tubuh menurun, serta gangguan pertumbuhan pada hewan usia muda (Lukiswanto dan Yuniarti, 2013). Sebanyak $85 \%$ dari kucing yang diare terinfeksi protozoa saluran pencernaan, sedangkan $64,3 \%$ kucing yang tidak mengalami diare terinfeksi protozoa saluran pencernaan. Hal tersebut menunjukkan mayoritas kucing yang terinfeksi protozoa saluran pencernaan akan mengalami diare. Menurut Lukiwanto dan Yuniarti (2013) diare pada kucing disebabkan adanya gangguan atau penyakit pada intestinal. Prevalensi infeksi protozoa saluran pencernaan berdasarkan kondisi feses tertera pada Tabel 7.

Tabel 7. Prevalensi Infeksi Protozoa Saluran Pencernaan Berdasarkan Kondisi Feses

\begin{tabular}{|c|c|c|c|}
\hline $\begin{array}{l}\text { Kondisi } \\
\text { Feses }\end{array}$ & Spesies & $\begin{array}{l}\text { Jumlah } \\
\text { Positif }\end{array}$ & $\begin{array}{l}\text { Prevalensi } \\
\text { (\%) }\end{array}$ \\
\hline \multirow{4}{*}{ Diare } & $\begin{array}{l}\text { Blastocystis sp. } \\
\text { Cryptosporidium }\end{array}$ & $10 / 20$ & $50 \%$ \\
\hline & sp. & $8 / 20$ & $40 \%$ \\
\hline & Eimeria sp. & $2 / 20$ & $10 \%$ \\
\hline & Giardia sp. & $2 / 20$ & $10 \%$ \\
\hline Tidak & $\begin{array}{l}\text { Blastocystis sp. } \\
\text { Cryptosporidium }\end{array}$ & $38 / 70$ & $54,28 \%$ \\
\hline $\begin{array}{l}\text { Diare } \\
\text { (Feses }\end{array}$ & sp. & $5 / 70$ & $7,14 \%$ \\
\hline \multirow[t]{2}{*}{ Normal) } & Eimeria sp. & $2 / 70$ & $2,85 \%$ \\
\hline & Giardia sp. & $2 / 70$ & $2,85 \%$ \\
\hline
\end{tabular}

\section{Kesimpulan}

Angka prevalensi infeksi protozoa pada pasien kucing di beberapa Rumah Sakit Hewan dan Klinik Hewan di Surabaya adalah 68,89\%. Protozoa yang ditemukan menginfeksi kucing pasien Rumah Sakit Hewan Klinik Hewan Puppy di Surabaya adalah Eimeria sp, Cryptosporidium sp Giardia yakni Giardia sp dan Blastocystis sp. Perbedaan jenis kelamin, umur, ras dan kondisi feses tidak berpengaruh terhadap prevalensi infeksi protozoa saluran pencernaan. 


\section{Daftar Pustaka}

Bendryman, S. S. 200o. Prevalensi Infeksi Cacing dan Protozoa Saluran Pencernaan pada Kucing Liar di Kotamadya Surabaya. Faculty of Veterinary Medicine. Airlangga University.

Duda et al. 1998. Detection of Blastocystic sp in domestic dogs and cats. Australia. Veterinary Parasitology. Vol 9. No. 17 :10-15

Fiyah. 2015. Deteksi Protozoa Saluran Pencernaan Pada Kucing Peliharaan di Kotamadya Surabaya [Skripsi]. Universitas Airlangga.

Levine, N. D. 1995. Buku Pelajaran Parasitologi Veteriner, penerjemah: Gatut Ashadi, Wardiarto, editor. Yogyakarta: Gadjah Mada University Press.

Lukiswanto, B. S. dan W. M. Yuniarti. 2013. Pemeriksaan Fisik pada Anjing dan Kucing. Airlangga University Press.

Milliana, M. 2010. Prevalence of Stray Cats with Intestinal Protozoan Parasites. American Journal Animal \& Veterinary Science Vol 5 No 3: 86-9o.

Pabundu, D. 2007. Kasus Penyakit Hewan di Rumah Sakit Hewan Pendidikan Fakultas Kedokteran Hewan Universitas Airlangga Periode 2003-2006[Skripsi]. Fakultas Kedokteran Hewan. Universitas Airlangga.

Sucitrayani, P. T. E., I. B. M. Oka dan M. Dwinata. 2014. Prevalensi Infeksi Protozoa Saluran Pencernaan pada Kucing Lokal (Felis catus) di Denpasar. Buletin Veteriner Udayana. Vol:6, No. 2 : 153-159.

Susanty Y. 2005. Memilih dan Merawat Kucing Kesayangan. Jakarta : Agro Media Pustaka

Suwanti, L. T., N. D. R. Lastuti, E. Suprihati. 2012. Diktat Protozoologi Veteriner. Fakultas Kedokteran Hewan, Universitas Airlangga. Surabaya.
Wastomi, Z. N. 2014. Prevalensi dan Derajat Infeksi Cacing Saluran Pencernaan pada Kucing di Beberapa Pet Shop di Kota Surabaya [Skripsi]. Universitas Airlangga.

Yudhie2010. Kosidiosis pada Kuicng dan Anjing. http://yudhiestar.blogspot.com/2010/o1/kok sidiosis-pada-kucing-anjing.html [o1 Januari 2018]

Lukiswanto, B. S. dan W. M. Yuniarti. 2013. Pemeriksaan Fisik pada Anjing dan Kucing. Airlangga University Press. Milliana, M. 2010. Prevalence of Stray Cats with Intestinal Protozoan Parasites. American Journal Animal \& Veterinary Science Vol 5 No 3: 8690.

Pabundu, D. 2007. Kasus Penyakit Hewan di Rumah Sakit Hewan Pendidikan Fakultas Kedokteran Hewan Universitas Airlangga Periode 2003-2006 [Skripsi]. Fakultas Kedokteran Hewan. Universitas Airlangga.

Sucitrayani, P. T. E., I. B. M. Oka dan M. Dwinata. 2014. Prevalensi Infeksi Protozoa Saluran Pencernaan pada Kucing Lokal (Felis catus) di Denpasar. Buletin Veteriner Udayana. Vol:6, No. 2 : 153-159.

Susanty Y. 2005. Memilih dan Merawat Kucing Kesayangan. Jakarta : Agro Media Pustaka

Suwanti, L. T., N. D. R. Lastuti, E. Suprihati. 2012. Diktat Protozoologi Veteriner. Fakultas Kedokteran Hewan, Universitas Airlangga. Surabaya.

Wastomi, Z. N. 2014. Prevalensi dan Derajat Infeksi Cacing Saluran Pencernaan pada Kucing di Beberapa Pet Shop di Kota Surabaya [Skripsi]. Universitas Airlangga. 